\title{
Commentary: Embracing Culture as Essential to Pacific People
}

\author{
Halaevalu F.O. Vakalahi \\ George Mason University, USA
}

\begin{abstract}
$\mathrm{T}$ he existing written literature on Pacific people is generally limited and available information is often incomplete, inaccurate or outdated. In many geographical locations, including the United States, literature focusing specifically on Pacific people is extremely sparse because it is often subsumed within broader coverage of people throughout the Asia-Pacific region. As such, the experiences are often trivialised. The Journal of Pacific Rim Psychology is filling gaps in contemporary psychology. It is exposing the world to the phenomenally rich and diverse cultures and people of the Pacific Rim. This is not only groundbreaking; it is also a form of social justice work. It advocates the use of a cultural lens in viewing the world and human behaviour; in this case a Pacific-culture lens that emphasises inclusivity, collectivity and reciprocity. Helping to promote a social justice movement that celebrates and honours the rich and extraordinarily diverse region of the Pacific will continue to contribute to the betterment of research, services and programming in today's diverse society. Furthermore, it will contribute to the journal's quest to become a preferred forum for the ??First People of the Pacific inside and outside of their Pacific home.
\end{abstract}

Contemporary psychology's focus on linking disciplines to form a more multidisciplinary approach to human behaviour (Berry, 2003) has led to an inclusive perspective that is grounded in a person's connection to his/her culture and environment. That perspective operates across systems and considers social issues on an individual, local and global level of analysis. In particular, the recent special section innovation in this journal, focusing on cultural diversity across the Pacific, brings to life the importance of indigenous perspectives for the overall health and wellbeing of Pacific ??people in the Pacific, including their lives abroad. The three articles reviewed for this commentary speak to the urgency of expanding the existing literature to admit to the complexity of Pacific indigenous cultures. The three articles begin a process of informing our overall understanding and resolve to address the issues and opportunities in cultural diversity across the Pacific.

Professionals who work across disciplines and cultural lines are well-positioned to combat culture dominance and superior attitudes of dominant cultures; in addition, they can help to promote the acceptance of culture in psychology and cultural ways of thinking and doing. With an increase in global migration, there are no longer any justifications for culturally biased and insensitive behaviours, if there ever were. As discussed in the articles under review, insecurities about one's identity will hinder one's ability to be open to understanding and embracing the identity of others, thus decreasing the possibility of cross-cultural connections and mutual understanding (Berry, 2010; Furnham, 2010; Marsella \& Yamada, 2010). Professionals across all disciplines must be open to such possibilities.

Of outmost importance to Pacific people, regardless of generation and location, is the acknowledgment of the histories of colonisation and immigration and their impact (Kaholokula, Grandinetti, Keller, Nacapoy, Kingi, \& Mau, 2011). As referenced in these articles (Berry, 2010; Furnham, 2010; Marsella \& Yamada, 2010), contemporary psychology can make an important contribution to the current multidisciplinary work on cultural competency, as a means to ensure respectful quality of service and programming, which helps to produce healthy outcomes for Pacific people. Multidisciplinary advocacy like this, for cultural competency, must continue (Davis, 2008).

\section{'Culture Shock: Literature Review, Personal Statement and Relevance for the South Pacific' by Adrian Furnham}

\section{Article summary}

In this article, Furnham discussed the concept of culture shock from three perspectives. First, from an academic 
perspective, the concept of culture shock is discussed by a thorough literature review of half a century worth of research on the experiences of travel. The discussion is framed by bringing together views from across the disciplines of anthropology, education, psychiatry, psychology and sociology; by doing so, the author attempts to operationally define, and to gain a better understanding of, the process of culture shock. Culture is a serious challenge with dire consequences for overseas students who apparently fare worse than their native counterparts. Culture shock results from discrimination and prejudice, language barriers, financial stress, social isolation, adolescence/young adult developmental struggles and other maladaptive experiences. It often contributes to physical, psychological, social and academic problems that, in turn, link back to culture shock. With an understanding that adjustment can be based on both intra- and inter-individual factors, concepts of culture-distance and social support are offered as possible ways to understand and address the experiences of overseas students.

Second, immigration and emigration around the South Pacific and the consequences for large and small countries are discussed as they relate to foreign students, migrants and refugees. Migration for the purposes of political, educational and economic progress is predicted to increase from the 'new' Asia and to decrease from 'old' Europe. Regardless of the direction or reason for migration, experiences of culture shock, as well as social change or upheaval, will increase.

Finally, the author offers a personal perspective on his interest in this topic, which grew out of his upbringing and his own experiences with culture shock. Furnham lived in South Africa during apartheid, an era when skin colour and culture dictated one's life trajectory. Later, as a South African immigrant in England, he was treated as a foreigner outside of his country of origin.

\section{Comments}

One does not need to search far to recognise the massive increase in human migration around the world today. With such migration patterns, particularly in the Pacific, human cultures have become a more complex phenomenon requiring a level of humility that lends itself to a greater understanding of cultures of origin, host cultures and the intersection of the two. This increase in migration requires multifaceted advances in addressing negative consequences of migration such as culture shock. The complexity of human cultures, as well as its integral role in positive human relationships, legitimises the need for cultural humility (Ortega \& Faller, 2010) and a multidisciplinary perspective of critical issues linked to the nuances of culture shock.

Culture shock is of mutual concern to guest and host, new settler and old. For instance, a person-in-environment perspective (Hull \& Kirst-Ashman, 2004), a core perspective to the profession of social work, speaks of the interaction between and among systems and the consequences of such interactions. Essentially, this perspective promotes shared responsibility in that overseas students, families, institutions and communities in both countries of origin and host countries are collectively responsible for the outcomes of the students and vice versa. This perspective conceptualises combating cultural dominance and the superior attitude of the dominant culture through the concept of mutual culture shock.

For Pacific people in particular, the dual experiences of colonisation and immigration must be taken into account when examining culture shock because such experiences can be transmitted from one generation to the next and can lead to unhealthy outcomes. With advanced knowledge and accessibility to resources today, lessons about dealing with culture shock can be learnt by examining the experiences of overseas Pacific students across time and location. For example, the concept of social support, which may be a cultural lifeline for Pacific students and Pacific hosts, may be interesting to examine as a possible source of protection against the consequences of maladjustment and possible exclusion. In other words, are there Pacific cultural lifelines that can serve as a source of risk or protection for culture shock among this overseas student population and/or their hosts?

The author offered an interesting discussion on the concept of 'double-minority' status, which has major implications for any work on culture shock, especially among overseas students from across cultures. Double and treble minority status involves not only numerical minority status, but also discrimination and disadvantage in terms of ethnicity, gender and equal opportunity (Bilchik \& Stagner, 2009).

\section{'Intercultural Relations and Acculturation in the Pacific Region' by John W. Berry Article summary}

In this article, Berry provides an extensive discussion of the literature and theoretical frameworks on culture and behaviour in intercultural and acculturation psychology. By doing so, he integrates the acculturation experiences of immigrant youth in 13 different countries. He acknowledged the amazing cultural diversity within the Pacific region but also some of the potentially negative consequences of intercultural contact and acculturation. As one of the most culturally diverse areas in the world, the phenomena of intercultural relations and acculturation in the Pacific region are at the forefront of contemporary psychological interests. When cultures come in contact with each other, strategies to deal with culture shock include assimilation, separation, integration and marginalisation - with integration being the preferred strategy. Group dominance must be controlled 
and mutual accommodation is required for acculturation to produce successful outcomes.

Therefore, the more differentiated an individual's psychological, social and cultural lives, the better able he or she is to adapting to living in an intercultural environment and having more positive outcomes. Advancing multicultural ways of being and mutual accommodation are strategies for positive outcomes. That is, a multicultural framework that requires accommodating the interests of all cultural groups into a national framework, one that produces mutuality and reciprocity, maintains cultures and identities, and promotes full and equitable participation.

\section{Comments}

As affirmed through the work of Agnew, PulotuEndemann, Robinson, Suaalii-Sauni and Warren (2004) and Tamasese, Peteru, Waldegrave and Bush (2005), many Pacific people are relational beings legitimised by sacred relationships built on the values of tapu (sacred bonds), alofa (love and compassion), tautua (reciprocal service), fa'aloalo (respect and deference), fa'amaualalo (humility), and aiga (family); to them, culture is the core of their very existence, both individually and collectively. Nevertheless, being cognisant of the negative consequences of colonisation and forced acculturation among Pacific cultures is critical for working towards balanced intercultural relationships that can lead to positive outcomes for people of the Pacific. Of great relevance to this work is the collective, inclusive and reciprocal underpinning of this article that aligns with Pacific cultural values of shared responsibility, reciprocity, and interdependence.

There is a need within cross-cultural psychology to embrace differences as sources of strength - as opposed to sources of deficiency or superiority - that can contribute to mutually respectful cultural relationships. Respect for differences as a positive contributor to human development is critical during these current times of economic, social and political uncertainty for example, of forced mobility from Pacific Island homes due to rising sea levels, economic downturns and job losses. We are reminded in this article of the need to overcome our human tendency to be insecure about our own identities thus hindering our ability to accept others, whether we are in the economically, politically and/or culturally dominant group. Perhaps, as we embrace and celebrate our differences and uniqueness, we will ultimately find what connects us as human beings. This inclusive and collective perspective is critical for success in cross-cultural psychology work with Pacific cultures and people.

In reference to the author's discussion of positive intercultural relationships and acculturation, finding a healthy balance between what to preserve and what to change is the underlying nuts-and-bolts issue. Finding this balance does not require giving up one's original identity, but instead requires being adaptable and open to new experiences. This issue of finding balance between the new and the old, the same and the different, also speaks to whether one desires to respond through integration, assimilation, separation or marginalisation as a strategy for an intercultural relationship. As Sen (1999) has noted, development is about freedom, including the freedom to choose, on occasion, separation or assimilation, as well as integration rather than being marginalised involuntarily by others. 'Integration' is not always the choice it appears to be, on the surface. The current 'multicultural' environments of the Pacific have had a controversial history in terms of disrespect for cultures of origin and indigenous Pacific cultures, from the marginalisation of Indigenous Australians to the testing of nuclear warheads in Pacific waters. Additional work focusing on determining when and how strategies of integration, assimilation, separation and marginalisation can produce healthy outcomes for Pacific people is always welcomed.

\section{'Culture and Psychopathology: Foundations, Issues, Directions' by Anthony J. Marsella and Ann Marie Yamada}

\section{Article summary}

In this article, Marsella and Yamada defined culture and discussed some of the historical influences, conceptual assumptions and major findings associated with the interaction of culture and psychopathology. For instance, the authors discussed the limited applicability of traditional psychological diagnoses to some nonwestern cultures and further discussed a growing interest in the role of culture as a determinant of human behaviour. A resistance by psychology to integrating cultural considerations into the understanding and treatment of psychopathology is discussed, together with some landmark research and documents that support the importance of culture in shaping behaviour that leads to health and wellbeing. The article also cautions about the risks of imposing western cultural views, classifications and diagnoses across cultures as western psychiatric practices may be relevant only within western cultural contexts. Caution is offered about mistaking power and dominance for accuracy. Recommendations are offered for conducting cross-cultural research, particularly in relation to 'schizophrenic' disorders. The case of Native Hawaiians is discussed. Cultural competency and multilevel approaches to behaviour are emphasised.

\section{Comments}

As emphasised in this article, ignoring the profound impact of Pacific cultural values, beliefs and practices has been and will continue to be detrimental to the health, wellbeing and the very existence of Pacific people in and outside of the Pacific. There is no excuse for the 
resistance to accept sociocultural perspectives in psychopathology, given the prevalence of diversity and intercultural interaction in the world today. The common place of intercultural interactions and relationships across the globe makes the exclusion of cultural context in psychiatry and psychology unacceptable and perhaps, professional and ethically irresponsible.

This article is a call to action on behalf of the cultures of Pacific people. Prior to colonisation and immigration, Pacific people lived their lives supported by their indigenous cultural values, beliefs and practices (Oliver, 1951). Many indigenous Pacific world-views are holistic, collective and inclusive of the interface of physical, mental, social and spiritual dimensions of the self and cultural and environmental contexts. Indigenous Pacific cultures are often grounded on the centrality of family and community (Anae, Coxon, Mara, WendtSamu, \& Finau, 2001) and the collective interrelationship between Atua (God), tagata (people), and laufanua (environment, land). The person-in-environment perspective and the cultural aspects of health and illness are indeed integral to Pacific people. However, the sustaining nature of cultural lifelines for Pacific people have not been acknowledged and accepted in the field of psychology.

As warned by the author, unfortunately, power and dominance are often mistaken for accuracy, which consequently disregards the legitimacy of the cultural context of, and even more importantly for, Pacific people. The authors' denouncement of power and dominance as a rationale for resisting the influence of the cultural context in psychiatry and psychology correctly reflects an awareness of the danger of delegitimising the cultural experiences of Pacific people.

As reemphasised in this article, cultural competency and multilevel approaches are decades-old recommendations that are necessary for truly understanding the determinants of human behaviour and healthy outcomes of Pacific oeople (Braun, Yee, Mokuau, \& Browne, 2004). Cultural competency can be multidisciplinary and can translate to high standards, and quality services and programming. Identifying multiple determinants of human behaviour is not only critical for service, but demonstrates a respect for each person's and group's uniqueness and similarities. Continuing to ignore the importance of culture and cultural competency will continue to put Pacific individuals, families and communities at risk. The challenge is to enable and empower, not to diagnose and treat.

\section{Conclusion}

Although the focus is on cultures across the Pacific Rim, there is an urgency to accurately expand the written literature on Pacific people/Pacific Islanders. Research, programming and services informed by and relevant to Pacific people/Pacific Islanders continue to be in short supply in and outside of the Pacific. Thus, there is a bright future for this work. In fact, this discussion is timely for the current movement to reclaim and preserve cultures in the Pacific. This is not a threat to existing psychology, it is an opportunity. As referenced by the articles reviewed, the study of the cultures of Pacific people has much to offer psychology. However, it is critical for such study to understand the world-view of Pacific people in relation to their sacred sea of island homes (Hau'ofa, 1994), their dynamic cultural life ways and oral histories.

As indicated earlier, colonisation and immigration are historical experiences with consequences that continue to impact Pacific people today. Although colonisation and immigration have triggered the drastic evolution of Pacific cultures over generations and across geographical areas, these cultures' holistic, inclusive and collective underpinnings remain central to the lives of Pacific people today. Gaining a better understanding of cross-cultural psychology through indigenous cultural lenses that emphasise inclusivity, and that account for bio-psychosocial-spiritual dimensions is important for Pacific people.

This conceptualisation of Pacific people as relational beings offers an opportunity to consider a cultural view of the relationship between God, people and the environment. The special section therefore suggests an expanding foundation for more culturally competent psychological services, one that is increasingly needed in the Pacific region, and beyond.

\section{References}

Agnew, F., Pulotu-Endemann, F. K., Robinson, G., SuaaliiSauni, T., Warren, H., Wheeler, A., Erick, M., Hingano, T., \& Schmidt-Sopoago, H. (2004). Pacific models of mental health service delivery in New Zealand ("PMMHSD") project. Auckland, NZ: Health Research Council of New Zealand. Retrieved July 1, 2010 from http://www.tepou. co.nz/file/PDF/publications/Pacific\%20Models\%20Report \%20Final\%20Sept\%202004.pdf

Anae, M., Coxon, E., Mara, D., Wendt-Samu, T., \& Finau, C. (2001). Pasifika education research guidelines: Final report. Wellington, New Zealand: University of Auckland.

Berry, J.W. (2003). Ecocultural perspective on human psychological development. In T.S. Saraswathi (Ed.), Cross-cultural perspectives on human development: Theory, research and applications (pp. 51-69). New Delhi: Sage.

Bilchik, S., \& Stagner, M. (2009). Racial and ethnic disparity and disproportionality in child welfare and juvenile justice: $A$ compendium. Washington, DC: Center for Juvenile Justice Reform.

Braun, K., Yee, B., Mokuau, N., \& Browne, C. (2004). Native Hawaiian and Pacific Islander elders. In K. Whitfield (Ed.), Closing the gap: A report on minority aging (pp 47-59). Washington, DC: Gerontological Society of America.

Davis, M.E. (2008). Intergenerational caregiving: Family and long-term care. In C. Waites (Ed.), Social work practice with African American families (pp. 143-163). New York: Routledge.

Hau'ofa, E. (1994). Our sea of islands. The Contemporary Pacific: A Journal of Island Affairs, 6(1), 148-161. 
Hull, G.H., Jr., \& Kirst-Ashman, K.K. (2004). The generalist model of human services practice. Pacific Grove, CA: Brooks/Cole-Thomson Learning.

Kaholokula, J.K., Grandinetti, A., Keller, S., Nacapoy, A.H., Kingi, T.K., \& Mau, M.K. (2011). Association between perceived racism and physiological stress indices in Native Hawaiians. Journal of Behavior Medicine, 1-11.

Oliver, D. (1951). The Pacific Islanders. Cambridge: Harvard University Press.
Ortega, R., \& Faller, K. C. (2010). Training child welfare workers from a cultural humility perspective. Retrieved November 30, 2011 from www.ssw.umich.edu/public/currentProjects /rrcwp/finalReport.pdf

Sen, A. (1999). Development as freedom. Oxford, UK: Oxford University Press.

Tamasese, K., Peteru, C., Waldegrave, C., \& Bush, A. (2005). Ole Taeao Afua, the new morning: A qualitative investigation into Samoan perspectives on mental health and culturally appropriate services. Australian and New Zealand Journal of Psychiatry, 39, 300-309. 


\section{NEW RELEASE OUT NOW}

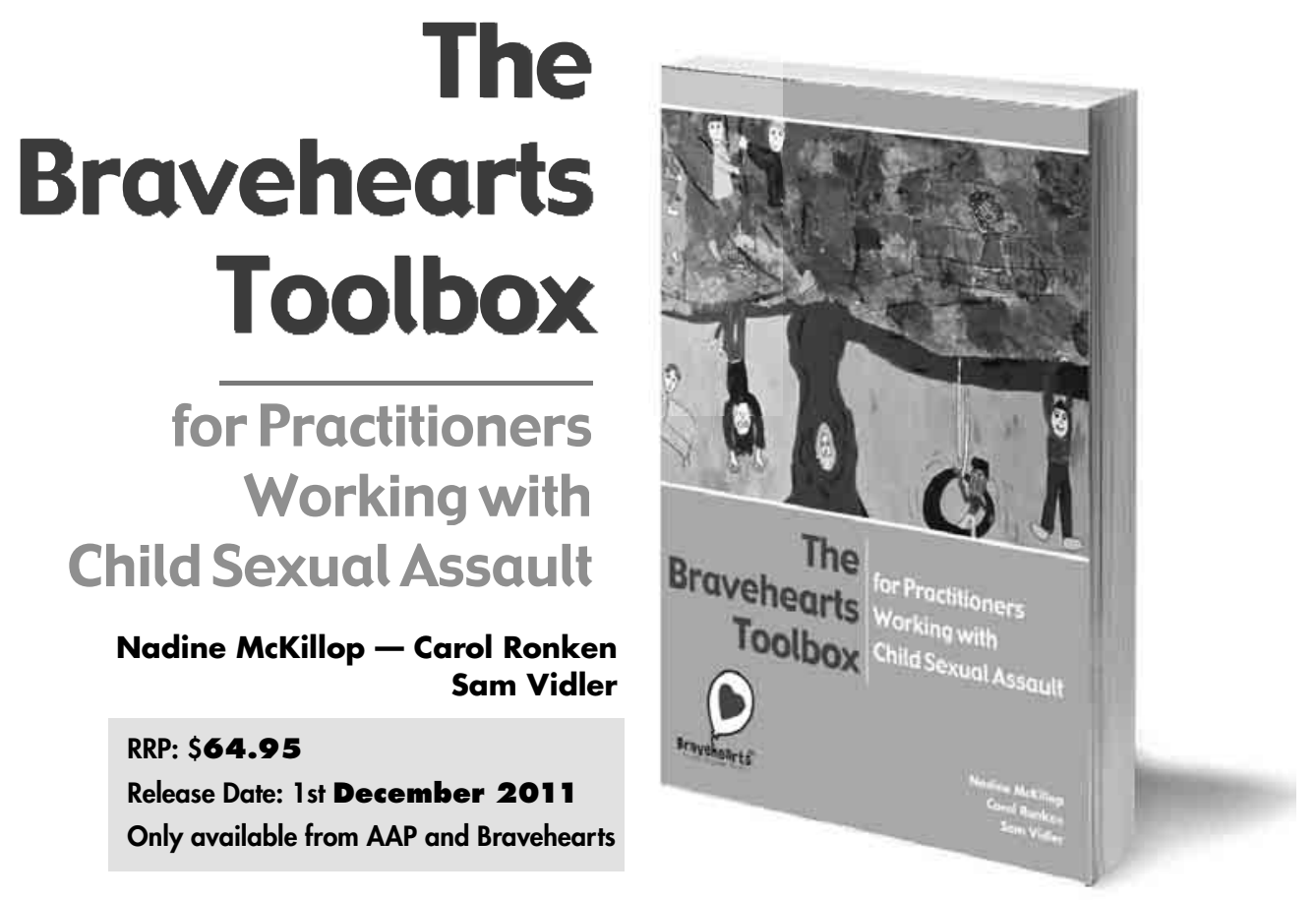

Combining the expertise of both researchers and practitioners specialising in the area of child sexual assault, this book provides an innovative, evidence-based approach to working with children and young people affected by sexual assault. It is an essential guide for general counsellors, school counsellors, psychologists, youth workers, chaplains, mental health practitioners and other allied health professionals, to provide them with the necessary information and skills to support children and young people affected by sexual assault. Its purpose is to build the confidence of these frontline workers and to reassure them that they do in fact possess the necessary skills to continue to work with their client once the issue of sexual assault has been raised.

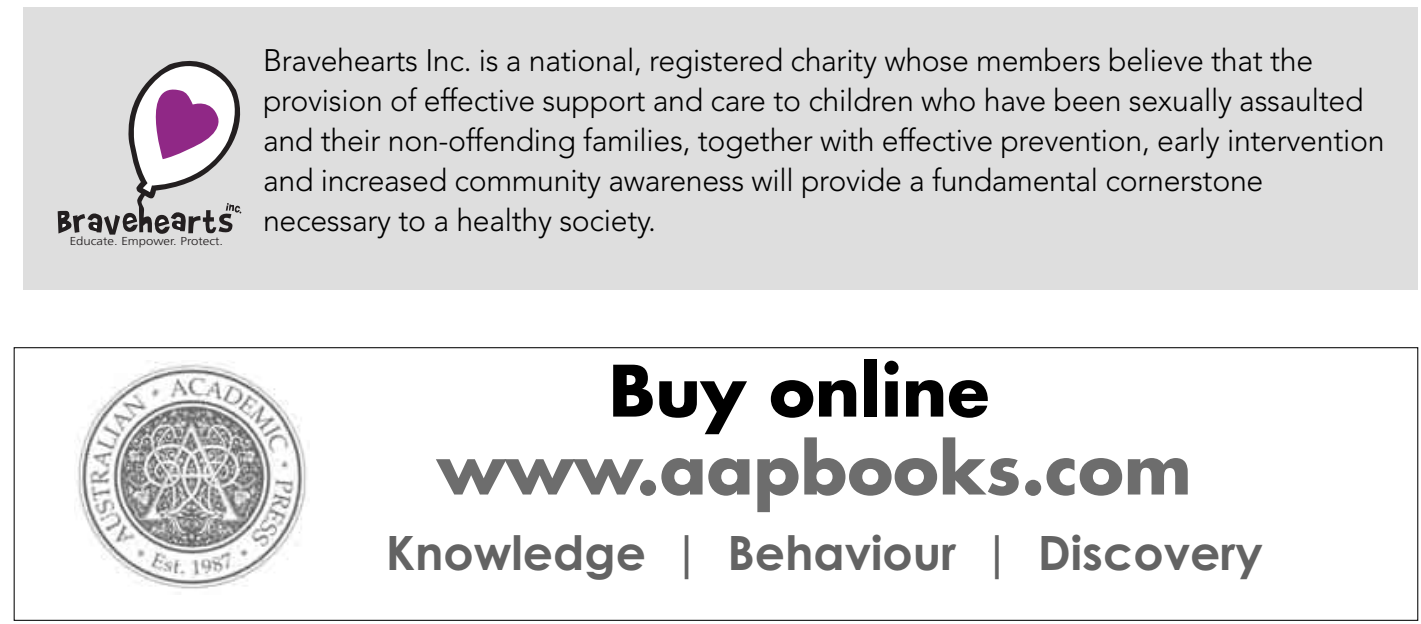

